\title{
Article \\ Intra-Tumour Genetic Heterogeneity and Prognosis in High-Risk Neuroblastoma
}

\author{
Amparo López-Carrasco ${ }^{1,2}$, Ana P. Berbegall ${ }^{1,2}$, Susana Martín-Vañó ${ }^{1,2}$, Maite Blanquer-Maceiras ${ }^{1,2}$, \\ Victoria Castel $^{3}$ (D), Samuel Navarro ${ }^{1,2}$ and Rosa Noguera $1,2, *$ (D) \\ 1 Department of Pathology, Medical School, University of Valencia-INCLIVA, 46010 Valencia, Spain; \\ amparolopezcarrasco@gmail.com (A.L.-C.); ana.berbegall@uv.es (A.P.B.); susana.martin@uv.es (S.M.-V.); \\ maiteblanquer@gmail.com (M.B.-M.); Samuel.Navarro@uv.es (S.N.) \\ 2 CIBER of Cancer (CIBERONC), 28029 Madrid, Spain \\ 3 Clinical and Translational Oncology Research Group, Investigation Institute La Fe, 46026 Valencia, Spain; \\ castel_vic@gva.es \\ * Correspondence: Rosa.Noguera@uv.es
}

check for updates

Citation: López-Carrasco, A.; Berbegall, A.P.; Martín-Vañó, S.; Blanquer-Maceiras, M.; Castel, V.; Navarro, S.; Noguera, R.

Intra-Tumour Genetic Heterogeneity and Prognosis in High-Risk Neuroblastoma. Cancers 2021, 13, 5173. https://doi.org/10.3390/ cancers13205173

Academic Editor: Anne M. Bowcock

Received: 9 September 2021

Accepted: 12 October 2021

Published: 15 October 2021

Publisher's Note: MDPI stays neutral with regard to jurisdictional claims in published maps and institutional affiliations.

Copyright: (c) 2021 by the authors. Licensee MDPI, Basel, Switzerland. This article is an open access article distributed under the terms and conditions of the Creative Commons Attribution (CC BY) license (https:/ / creativecommons.org/licenses/by/ $4.0 /)$.
Simple Summary: Neuroblastoma (NB) is the most common extra-cranial solid paediatric cancer and is responsible for $15 \%$ of childhood cancer deaths. Patients with NB are characterized by presenting a very heterogeneous clinic (inter-tumoural heterogeneity) and also both spatial and temporal intratumour heterogeneity (ITH) reflected in their genetic aberrations, which may be the consequence of the coexistence of different microenvironments within the tumour. Applying pangenomic techniques to detect genomic aberrations in different biopsies (solid and liquid) of high risk NB (HR-NB) we have detected spatial ITH in a surprisingly high percentage (almost $40 \%$ ) of the studied cohort. Moreover, a positive association between this heterogeneity and survival has been found. Confirming these results, combining tumour material analysis in a large cohort of HR-NB will have a major impact in the genetic diagnosis routine procedure, and would also entail a revision of the prognosis of patients with ITH.

Abstract: Spatial ITH is defined by genomic and biological variations within a tumour acquired by tumour cell evolution under diverse microenvironments, and its role in NB patient prognosis is understudied. In this work, we applied pangenomic techniques to detect chromosomal aberrations in at least two different areas of each tumour and/or in simultaneously obtained solid and liquid biopsies, detecting ITH in the genomic profile of almost $40 \%$ of HR-NB. ITH was better detected when comparing one or more tumour pieces and liquid biopsy $(50 \%)$ than between different tumour pieces $(21 \%)$. Interestingly, we found that patients with ITH analysed by pangenomic techniques had a significantly better survival rate that those with non-heterogeneous tumours, especially in cases without MYCN amplification. Moreover, all patients in the studied cohort with high ITH (defined as $50 \%$ or more genomic aberration differences between areas of a tumour or simultaneously obtained samples) survived after 48 months. These results clearly support analysing at least two solid tumour areas (separately or mixed) and liquid samples to provide more accurate genomic diagnosis, prognosis and therapy options in HR-NB.

Keywords: SNPa; ctDNA; segmental chromosomal aberration; genomics; $M Y C N$ amplification; tumour microenvironment

\section{Introduction}

In addition to genetic and clinical inter-tumour heterogeneity, which refers to variations found between different patients in tumours and/or behaviour, tumours can also present with spatial and/or temporal intra-tumour heterogeneity (ITH). Spatial genomic ITH is characterised by genomic variations within a tumour lesion, or between different tumours located in the patient at the same time point in the case of metastatic disease, 
and consists of multiple cells or sub-clones, each possessing different genomic profiles [1]. Temporal genomic ITH denotes genetic variation over the course of disease progression and has been observed mainly when comparing treatment-naïve and matched relapsed tumours [2]. Both ITH types can be a result of clonal evolution due to natural selection among tumour cells, or in the absence of strong selection can also emerge through the mechanism of genetic drift $[2,3]$. This diversity most likely arises as a way for the tumour to adapt to changing microenvironmental conditions and/or as a tool for altering its malignant potential [4].

In neuroblastoma (NB), ITH has been associated with a spectrum from favourable to unfavourable patient outcomes $[5,6]$. NB is the most common extra-cranial solid paediatric cancer and is responsible for $15 \%$ of childhood cancer deaths [7]. The International NB Risk Group (INRG) [8] has defined a currently-used prognosis classification according to clinical and biological parameters. Patients classified as high risk NB (HR-NB) have the poorest outcomes, with $<50 \%$ survival [9]. Adverse prognostic factors include metastatic stage, age $\geq 18$ months at diagnosis, undifferentiated or poorly differentiated histopathology and specific genetic abnormalities, such as MYCN amplification (MNA) and segmental chromosomal aberrations (SCAs) [10]. Recent molecular classifications have added new markers such as ALK, TERT, ATRX, TP53 and alternative lengthening of telomeres (ALT) abnormalities, to typify around $80 \%$ of HR-NB [11]. Tumour microenvironment (TME) and particularly extracellular matrix (ECM) features are also emerging as important factors contributing to tumour prognosis and heterogeneity [12,13]. In this regard, our group has previously described a common aggressive pattern of rigid ECM in HR-NB [14], rich in cross-linked collagen III fibres, poor in glycosaminoglycans, supporting sinusoidal vascular structures (blood and lymphatic) and with a high amount of territorial vitronectin (located in cytoplasmic compartments and a thin layer around tumour cells) [15-18]. In a recent study we observed the dramatic impact of ECM stiffness on ITH and clonal evolution of a MNA NB cell line, in which dominant clones were selected when cultured in stiff 3D-bioprinted hydrogels and in xenograft tumours; these changes were not found in an ALK mutated NB cell-line [3,19]. A continuous interplay therefore exists between TME and genetics, tumour cell proliferation, aggressiveness and migration [20].

In circulating tumour DNA (ctDNA) studies, liquid biopsy is viewed as an emerging tool for identifying genetic alterations across the whole tumour, and is particularly significant in highly heterogeneous neoplasia. Generally, HR-NB has been shown to release large quantities of ctDNA [21]. In fact, recent studies have demonstrated broad ITH when comparing ctDNA with DNA from NB tissue using high-throughput techniques, suggesting liquid biopsy as a promising source of material for genetic diagnosis [21,22]. However, liquid biopsy for tumour biopsy genetic analysis can be influenced by TME [23], possibly resulting in an underestimated number of cases of non-detected ITH, and aberrations driving tumour progression or therapy resistance could therefore remain hidden [24].

ITH of both MNA (hetMNA) and typical deletion at 1p36 of the NB have been detected by fluorescence in situ hybridisation (FISH) in different studies [5,25], one of which reports hetMNA as the apparent culprit of aggressive local growth and development of metastases in patients $\geq 18$ months of age at diagnosis [5]. Moreover, ITH has also been detected in other large SCAs, as well as in single nucleotide variations (SNVs), such as those of the ALK gene $[21,22,26,27]$. ITH is commonly associated with progressive disease and treatment resistance, likely because of selection of treatment-resistant clones [2]. However, whether intra-tumoral diversity data can be used to predict clinical outcome has until now remained unclear [28].

In this paper we document an in-depth study of spatial ITH, including several pieces of MYCN non-amplified (non-MNA), homogeneously amplified (MNA), and hetMNA primary HR-NB tumours. We applied pangenomic techniques to detect chromosomal aberrations in multiple areas of each tumour and/or in ctDNA from liquid biopsies. Our results highlight the need to analyse at least two solid tumour areas and liquid samples to 
gain an overview of the entire chromosome landscape at a particular time point, which provides more accurate genomic diagnosis, prognosis and therapy options.

\section{Materials and Methods}

\subsection{Patients and Samples}

A total of 129 samples from 58 NB patients diagnosed between 2002 and 2018 were included in this study, all classified as HR-NB following INRG criteria [8]. Diagnostic biopsy analysis found 32 cases of non-MNA, 20 of MNA and six of hetMNA. We analysed 93 DNA samples from frozen or formalin-fixed paraffin-embedded (FFPE) fragments and 36 ctDNA samples from liquid biopsy (peripheral blood or bone marrow) (Table 1). Given the aim of this work to study spatial ITH, liquid biopsy samples were collected at the same time as the corresponding primary tumours to avoid temporal ITH.

Table 1. Intratumor heterogeneous (ITH) cases according to total high-risk neuroblastomas (HR-NB) studied, their genomic profile (MYCN non-amplified, non-MNA; MYCN amplified, MNA; or with heterogeneous amplification of MYCN, hetMNA) and the combination of samples analysed in each case.

\begin{tabular}{|c|c|c|c|}
\hline $\begin{array}{c}\text { ITH Cases/Total HR-NB } \\
\text { Cases }\end{array}$ & $\begin{array}{c}\text { ITH Cases/Total Genomic } \\
\text { Profile Cases }\end{array}$ & \multicolumn{2}{|c|}{ ITH Cases/Combination of Samples Analysed } \\
\hline \multirow{14}{*}{ 22/58 HR-NB (37.9\%) } & \multirow{4}{*}{$14 / 32$ non-MNA ( $44 \%$ ITH) } & $2 / 13(15.4 \%)$ & $\mathrm{T} 1+\mathrm{T} 2$ \\
\hline & & $11 / 17(64.7 \%)$ & $\mathrm{T}+\mathrm{LB}$ \\
\hline & & - & $7 / 8 \mathrm{~T} 1+\mathrm{LB}$ \\
\hline & & & $4 / 9 \mathrm{~T} 1+\mathrm{T} 2+\mathrm{LB}$ \\
\hline & \multirow{5}{*}{ 8/20 MNA (40\% ITH) } & $1 / 2(50.0 \%)$ & $\mathrm{LBp}+\mathrm{LBm}$ \\
\hline & & $3 / 6(50.0 \%)$ & $\mathrm{T} 1+\mathrm{T} 2$ \\
\hline & & $5 / 14(35.7 \%)$ & $T+L B$ \\
\hline & & - & $5 / 13 \mathrm{~T} 1+\mathrm{LB}$ \\
\hline & & - & $0 / 1 \mathrm{~T} 1+\mathrm{T} 2+\mathrm{LB}$ \\
\hline & \multirow{5}{*}{$0 / 6$ hetMNA ( $0 \%$ ITH) } & $0 / 5(0.0 \%)$ & $\mathrm{T} 1+\mathrm{T} 2$ \\
\hline & & & $0 / 4 \mathrm{~T} 1+\mathrm{T} 2$ \\
\hline & & \multirow{3}{*}{$0 / 1(0.0 \%)$} & $0 / 1 \mathrm{~T} 1+\mathrm{T} 2+\mathrm{T} 3$ \\
\hline & & & $\mathrm{T}+\mathrm{LB}$ \\
\hline & & & $0 / 1 \mathrm{~T} 1+\mathrm{T} 2+\mathrm{T} 3+\mathrm{LB}$ \\
\hline- & - & \multirow{3}{*}{ Total } & $93 \mathrm{~T}$ \\
\hline- & - & & $36 \mathrm{LB}$ \\
\hline- & - & & 129 samples \\
\hline
\end{tabular}

T: solid tumor (1, 2, 3); LB: liquid biopsy, LBp: liquid biopsy from peripheral blood, LBm: liquid biopsy from medullary aspirate.

All samples were sent to the Spanish Reference Centre for NB Molecular and Pathological studies (Department of Pathology, University of Valencia-INCLIVA). Histopathological data were provided by the group pathologist. Clinical data were provided by the attending paediatric oncologist where possible, or by the Reference Centre for NB Clinical Studies, including outcome data on event free survival (EFS), defined as length of time from date of diagnosis to any progression, death or to the date of last contact; and overall survival (OS), defined as length of time from date of diagnosis until death or last medical check-up in surviving patients.

\subsection{MYCN, 1p and 11q Status Detected by FISH}

FISH analyses for the MYCN gene were performed on tumour imprints and/or FFPE sections of the tumour with MYCN (2p24)/ AFF3 (2q11) (KreatechTM, Amsterdam, Netherlands) probe and 4,6-diamidino-2-phenylindole (DAPI) probe as a counterstain. Definition of MNA versus hetMNA samples was as previously described [5]: all malignant neuroblasts of the sample with MNA (some MYCN gain also allowed), versus some with MNA and others with whole or numerical copy number anomalies of chromosome 2. FISH of $1 \mathrm{p}$ and 11q regions were also performed in most samples, with the SRD (1p36)/SE1 and 
KMT2A/SE11 (KreatechTM, Amsterdam, Netherlands) probes, respectively. FISH results were completed with pangenomic techniques.

\subsection{DNA and ctDNA Extraction}

DNA from 83 frozen and 10 FFPE tumours was extracted as described elsewhere [29]. A ctDNA study was carried out on 36 plasma samples extracted with QIAamp Circulating Nucleic Acid (Qiagen, Manchester, UK) kit, following the provided protocol.

\subsection{SNPa and HD-SNPa Pangenomic Analysis of Tumour Samples}

The vast majority of tumour samples (112) were analysed using different high density single nucleotide polymorphism arrays (HD-SNPa): Affymetrix kits used were CytoScan HD DNA for frozen tumours, and OncoScan CNV gene chips for DNA from FFPE tumors and for ctDNA from plasma samples, following by analyses using Chromosome Analysis Suite 3.2 (ChAS) software (ThermoFisher Scientific, Waltham, MA, USA) and Nexus 10.0 Copy Number Discovery (BioDiscovery, El Segundo, CA, USA). The Illumina kits (California, USA) used were HumanCytoSNP-12 for frozen tumour DNA samples and HumanCytoSNP FFPE-12 for FFPE ones, following analysis with GenomeStudio and KaryoStudio software, version 1.4. Only 12 tumour DNA samples were analysed by SNPa with GeneChip Human Mapping 250K (ThermoFisher Scientific, Waltham, MA, USA). Primary data analysis was performed using GDAS 3.0.2 software (ThermoFisher Scientific, Waltham, MA, USA), while genomic profiles were generated using CNAG (Copy Number Analyzer for Affymetrix GeneChip Mapping arrays) version 3.0, with the AsCNAR function (allele-specific copy-number analysis using anonymous references). DNA amplification, tagging and hybridization to gene chips were performed according to the manufacturer's protocol.

\subsection{MLPA Analysis of Tumour Samples}

Only five tumour DNA samples belonging to five patients were analysed with this technique and were compared to HD-SNPa results to study ITH. MLPA was performed using the SALSA MLPA Kit P251/P252/P253 developed by MRC-Holland in cooperation with the International Society of Paediatric Oncology European Neuroblastoma (SIOPEN). The technique and interpretation guidelines are as described elsewhere [30].

\subsection{ALK Mutations and ALT Status}

$A L K$ mutations were studied in 37 out of 58 cases, using Sanger, next generation sequencing (mean depth $80 \times$ ), or targeted deep sequencing (TDS) approaches. All detected mutations were validated by a second independent experiment [31]. Alternative lengthening of telomeres (ALT) were analysed using c-circle assay [32] in 17 of 58 tumours, all non-MNA.

\subsection{Statistical Analysis}

All data were analysed using SPSS analysis software (version 26). Pearson's $\chi 2$ statistic was used to identify differences in frequency of each genomic aberration between HR-NB groups. $p$-values under 0.05 were considered statistically significant. Survival analyses were carried out using Kaplan-Meier curves. Additionally, multivariate Cox regression analysis was undertaken with stepwise, forward and backward (Wald) methods to calculate the impact of ITH on patient survival.

\section{Results}

\subsection{Combined Samples HD-SNPa Revealed High ITH}

Among the 58 HR-NB cases included in our study, 22 cases (37.9\%) had ITH from the SCAs observed in pangenomic analysis between patient samples, from either tumour or liquid biopsy (Table 1 and Figures 1-3). Specifically, we found ITH by SNPa in 14 out of 32 
non-MNA cases (44\%), in eight out of 20 MNA HR-NB cases (40\%) but not in either of the hetMNA cases (Table 1 ).
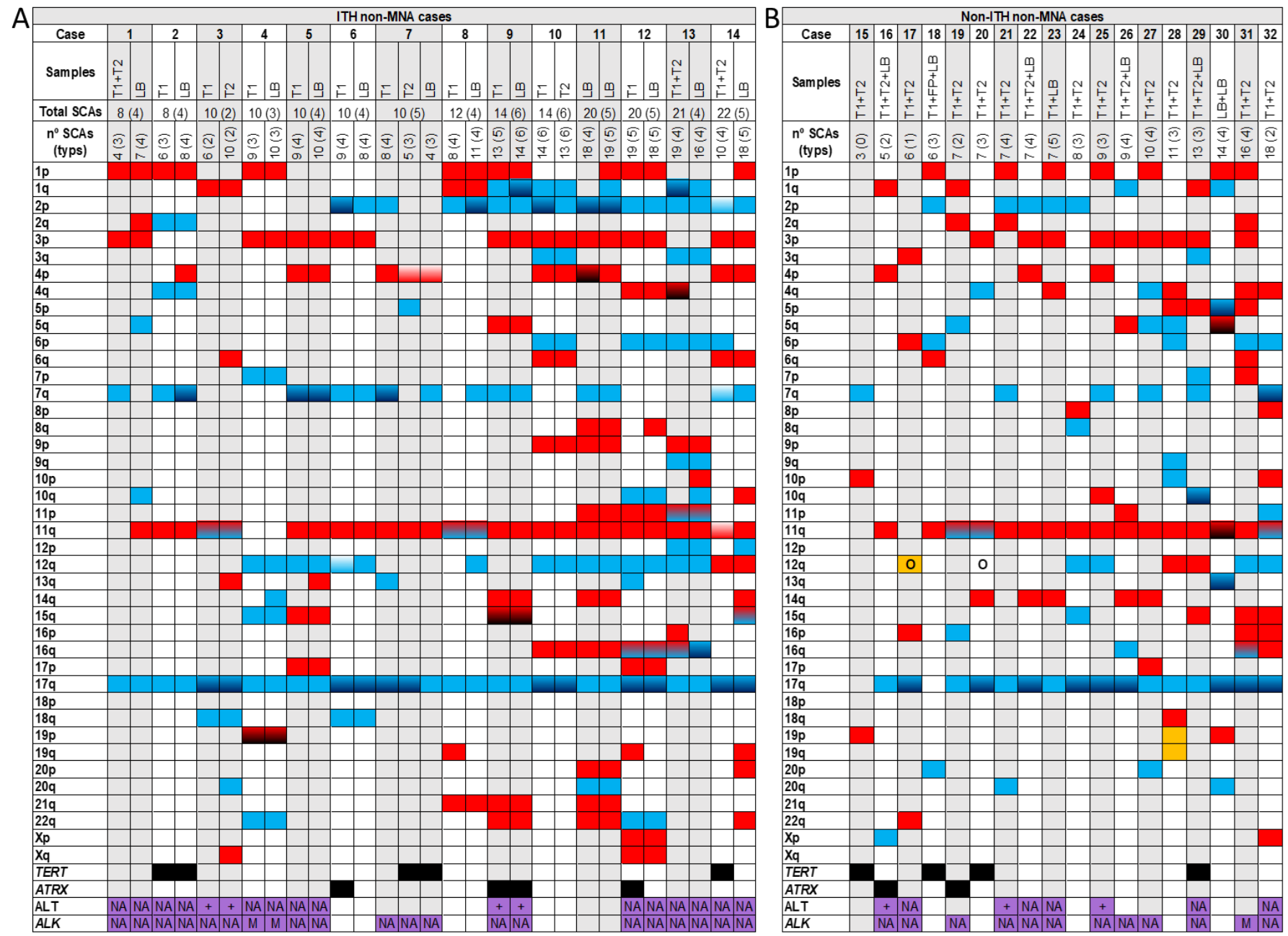

Figure 1. Genomic aberrations found by SNPa in $M Y C N$ non amplified cases (non-MNA) with intra-tumour heterogeneity (ITH) (A) and non-ITH (B). In the upper part of both Figures A and B the analysed samples (T: solid tumour -1, 2-; LB: liquid biopsy) corresponding to each case (1-32) with the total number of segmental chromosomal aberrations (SCAs) and the typical ones in parenthesis, are shown. In Figure 1A the total number of SCAs and typical ones of each case, taking into account all the analysed samples, are also presented. Solid blue $\square$ or red $\square$ squares refers to gains or losses, respectively in the indicated chromosome arm. Gradient color from blue $\square$ or red $\square$ to black indicates gains or losses with two or more chromosome fragments in the chromosome arm. Gradient color from white to blue $\square$ or red $\square$ indicates changes in the break position (which results in size variations of the aberration) in the chromosome arm between the analyzed samples of a case (only in ITH ones). Gradient color from blue to red $\square$ refers to both gains and losses in the same chromosome arm of a sample. Solid yellow $\square$ squares indicate the presence of a chromotripsis-like phenomenon. Black squares $\square$ indicate the presence of focal segmental chromosomal aberrations (FSCAs) affecting TERT or ATRX genes. Purple squares $\square$ indicate that the samples have been analysed for alternative lengthening of telomeres (ALT) or for mutations and amplifications in the $A L K$ gene; NA: in the squares indicates that any aberration has been detected in the sample; + : refers to the presence of ALT; A: refers to presence of $A L K$ amplification; M: indicates ALK mutation. O: indicates amplification of any gene or region in the chromosome arm, excluding $M Y C N$ or $A L K$ amplification. 

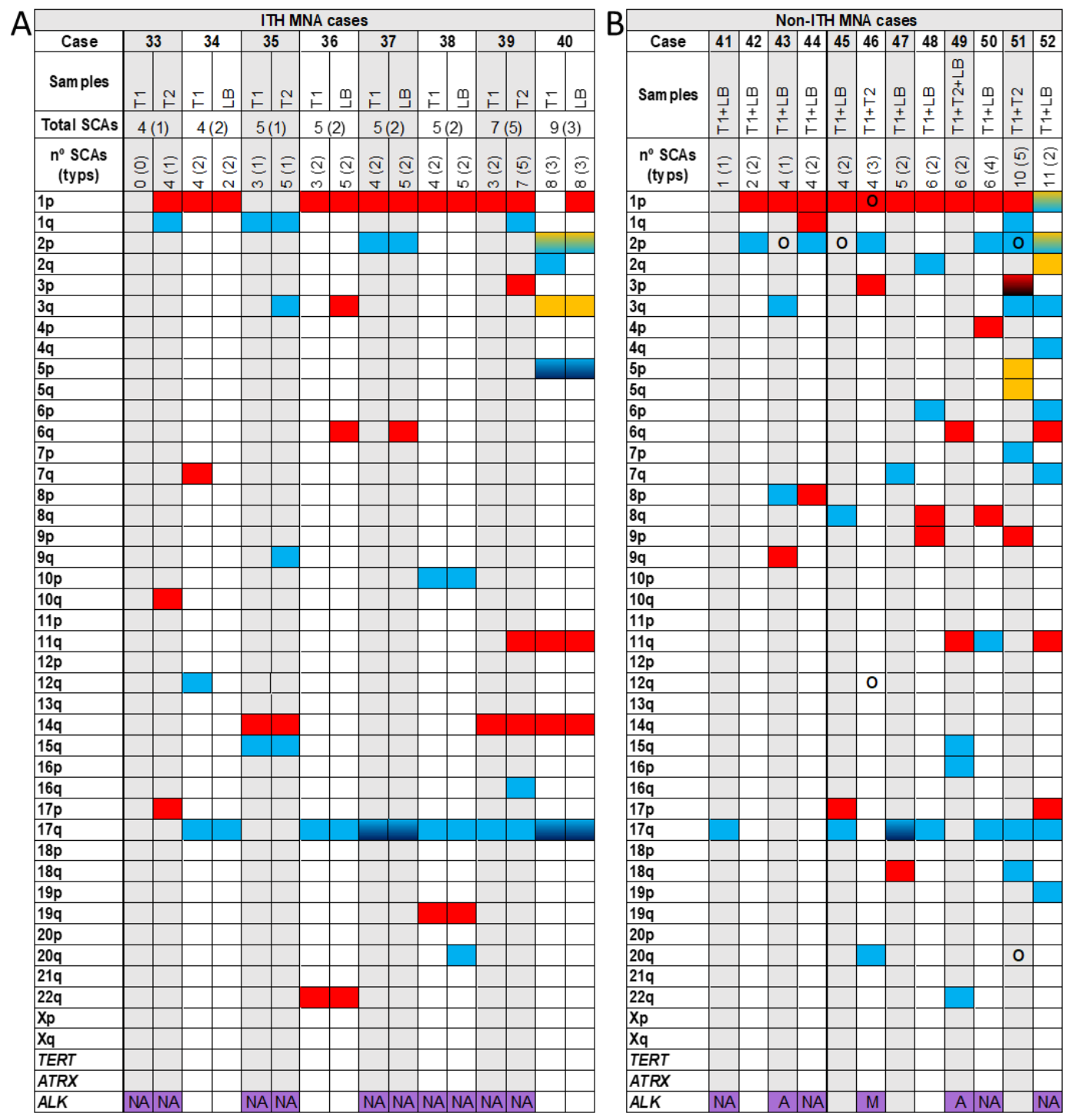

Figure 2. Genomic aberrations found by SNPa in MYCN amplified cases (MNA) with intra-tumour heterogeneity (ITH) (A) and non-ITH (B). In the upper part of both Figures A and B the analysed samples (T: solid tumour -1,2-; LB: liquid biopsy) corresponding to each case (33-52) with the total number of segmental chromosomal aberrations (SCAs) and the typical ones in parenthesis, are shown. In Figure 2A the total number of SCAs and typical ones of each case, taking into account all the analysed samples, are also presented. Solid blue $\square$ or red $\square$ squares refers to gains or losses, respectively, in the indicated chromosome arm. Gradient color from blue $\square$ or red $\square$ to black indicates gains or losses with two or more chromosome fragments in the chromosome arm. Solid yellow $\square$ squares indicate the presence of a chromotripsis-like phenomenon, and gradient color from yellow to blue $\square$ refers to chromotripsis-like phenomenon within a gain. Purple $\square$ squares indicate that the samples have been analysed for mutations and amplifications in $A L K$ gene; NA: in the squares indicates that any aberration has been detected in the sample; A: referes to presence of $A L K$ amplification; M: indicates $A L K$ mutation. O: indicates amplification of any gene or region in the chromosome arm, excluding MYCN or $A L K$ amplification. 


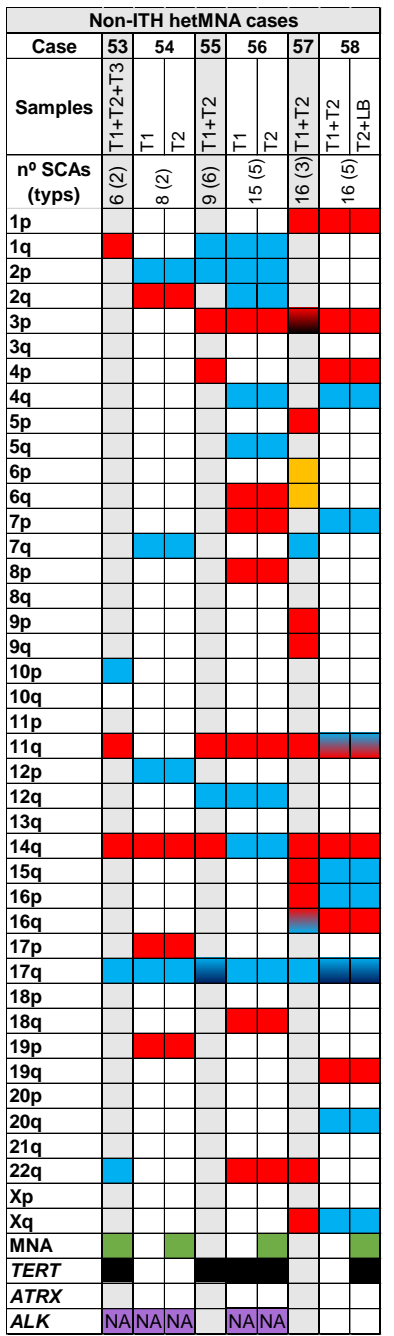

Figure 3. Genomic aberrations found by SNPa in cases with heterogeneous $M Y C N$ amplification (hetMNA). In the upper part the number of the analysed samples (T: solid tumour -1, 2, 3-; LB: liquid biopsy) corresponding to each case (53-58) with the total number of SCAs and the typical ones in parenthesis, are shown. Solid blue $\square$ or red $\square$ squares refers to gains or losses, respectively in the indicated chromosome arm. Gradient color from blue $\square$ or red $\square$ to black indicates gains or losses with 2 or more chromosome fragments in the chromosome arm. Gradient color from blue to red $\square$ refers to both gains and losses in the same chromosome arm of a sample. Solid yellow squares $\square$ indicate presence of chromotripsis-like phenomenon. Green squares $\square$ indicate MYCN amplification detection by SNPa. Black squares $\square$ indicate presence of focal segmental chromosomal aberrations (FSCAs) affecting TERT or ATRX genes. Purple squares $\square$ indicate that the samples have been analysed for alternative lengthening of telomeres (ALT) or for mutations and amplifications in $A L K$ gene; NA: in the squares indicates that any aberration has been detected in the sample.

Different solid areas of the same tumour were analysed in 24 out of 58 cases (49 out of 93 studied DNA samples), and five of them (21\%) showed ITH: 13 tumours were non-MNA, of which only two had ITH (15\%), six were MNA and three of them presented ITH $(50 \%)$ and the remaining five were hetMNA, in which HD-SNPa found no differences in SCAs (Table 1). We analysed only liquid biopsies (from peripheral blood or bone marrow aspirate) in two non-MNA tumours, one of which had ITH (Figure 1A,B). We detected ITH in $16(50 \%)$ of the 32 cases in which one or more solid plus liquid biopsies were analysed (in total, 44 out of 93 analysed DNA samples from different tumour areas, plus 32 out of 36 studied ctDNA samples). Among the 32 cases with both type of samples analysed, 17 were non-MNA, showing ITH in 11 cases (65\%); 14 were MNA, five of which presented 
with ITH (36\%), and one was an hetMNA case without ITH (Table 1). Among the 16 cases with ITH, in 10 we detected more SCAs in liquid than in solid samples, while in five cases the opposite was true. The remaining case showed an equal number of SCAs, but with between-sample differences in some SCAs (Figure 2A, case 40).

Of the 6 hetMNA cases (Figure 3), none showed ITH as reflected in SCAs from the different samples analysed by HD-SNPa. However, FISH of those tumours showed heterogeneity in MYCN amplification and also in loss at 1p (Figure 3, cases 53 and 54) or loss at 11q (Figure 3, case 58).

The number of chromosomal aberrations in ITH cases ranged from 4 to 23, with an average of 3.55 genomic events which differed between ITH tumour samples (an average of $36 \%$ differing genomic events) (Table 2). Besides differential presence/absence of SCAs, we also observed heterogeneous cell clones with shifts in the chromosome break position in 3 tumours, and presence of additional chromosome breaks in broken chromosomal regions in 5 cases, apparently resulting in altered SCA size. In addition, we detected ITH of FSCAs (focal SCAs $<3 \mathrm{Mb}$ ) in TERT (2 non-MNA cases) and ATRX genes (2 non-MNA cases). Presence of any of these genomic aberrations was considered a genomic event for statistical analysis. Finally, only one genomic event, gain at 12q, was significantly positively associated with ITH ( $p$-value $=0.014)$, but this event was not associated with survival.

Table 2. Genomic events and survival data in intra-tumour heterogeneous (ITH) cases. Cases with high ITH (with $50 \%$ or more of genomic events different between the analysed samples) are highlighted.

\begin{tabular}{|c|c|c|c|c|c|c|c|}
\hline Case & $\begin{array}{c}\text { Total N } \\
\text { Genomic Events } \\
\end{array}$ & $\begin{array}{l}\text { N Diff. Genomic Events between } \\
\text { Samples }\end{array}$ & $\begin{array}{c}\% \text { Diff. } \\
\text { Genomic Events } \\
\end{array}$ & EFS (Months) & Relapse/Death & $\begin{array}{c}\text { OS } \\
\text { (Months) }\end{array}$ & Death \\
\hline 1 & 8 & 5 & 62.50 & 92 & No & 92 & No \\
\hline 2 & 9 & 2 & 22.22 & 37 & Yes & 60 & Yes \\
\hline 3 & 10 & 4 & 40.00 & 23 & Yes & 46 & Yes \\
\hline 4 & 10 & 1 & 10.00 & 16 & Yes & 48 & Yes \\
\hline 5 & 10 & 1 & 10.00 & 129 & No & 129 & No \\
\hline 6 & 11 & 3 & 27.27 & 27 & Yes & 55 & No \\
\hline 7 & 11 & 8 & 72.73 & 98 & No & 98 & No \\
\hline 8 & 12 & 5 & 41.67 & 20 & Yes & 23 & Yes \\
\hline 9 & 15 & 1 & 6.67 & 17 & Yes & 57 & Yes \\
\hline 10 & 14 & 1 & 7.14 & 12 & Yes & 25 & Yes \\
\hline 11 & 20 & 4 & 20.00 & 61 & No & 61 & No \\
\hline 12 & 21 & 4 & 19.05 & 22 & Yes & 22 & Yes \\
\hline 13 & 21 & 7 & 33.33 & 22 & Yes & 32 & Yes \\
\hline 14 & 23 & 14 & 60.87 & 104 & No & 104 & No \\
\hline 33 & 4 & 4 & 100.00 & 127 & No & 127 & No \\
\hline 34 & 4 & 2 & 50.00 & 71 & No & 71 & No \\
\hline 35 & 5 & 2 & 40.00 & 31 & Yes & 31 & Yes \\
\hline 36 & 5 & 2 & 40.00 & 42 & No & 42 & No \\
\hline 37 & 5 & 1 & 20.00 & 7 & Yes & 10 & Yes \\
\hline 38 & 5 & 1 & 20.00 & 11 & Yes & 11 & Yes \\
\hline 39 & 7 & 4 & 57.14 & 48 & No & 48 & No \\
\hline 40 & 11 & 2 & 18.18 & 65 & No & 65 & No \\
\hline Average & 10.95 & 3.55 & 35.40 & 49.18 & - & 57.14 & - \\
\hline Median & 10.00 & 2.50 & 30.30 & 34.00 & - & 51.50 & - \\
\hline
\end{tabular}

\subsection{High Average Number of SCAs in ITH Non-MNA Samples}

All the studied tumours presented SCA profiles, with an average of 9.2 and a median of 8 SCAs. However, we observed a significant difference $(p$-value $<0.01)$ in the number of SCAs between tumour types related MYCN status when we distributed data into quartiles, with ITH non-MNA tumours having more SCAs (average 13.3, Figure 1A) than non-ITH non-MNA ones (average 8.8, Figure 1B). Within MNA cases we found similar average SCAs in ITH and non-ITH cases (5.5 and 5.3, respectively, Figure 2A,B). Finally, hetMNA had an average of 11.7 SCAs (similar to non-MNA, Figure 3).

Across the whole cohort, in addition to the high number of the typical SCAs, we found considerable incidence of certain atypical SCAs: $+6 p, 6 q-,+7 q,+12 q$ and $14 q-$ (Figure 4A). Some SCAs showed significant differences $(p<0.05)$ in frequency between non-MNA, MNA and hetMNA tumours. Most notable among the typical SCAs were losses at $3 p$ and $4 p$, while gains at $7 q$ and $12 q$ were predominant among the atypical ones with more prevalence in non-MNA and hetMNA cases. As is already known, 11q- is also less common in MNA tumours (Figure 4B). Curiously, $14 q-$ was present in $5(83 \%)$ of the hetMNA cases; this SCA was only present in a few tumours of the remaining groups. 

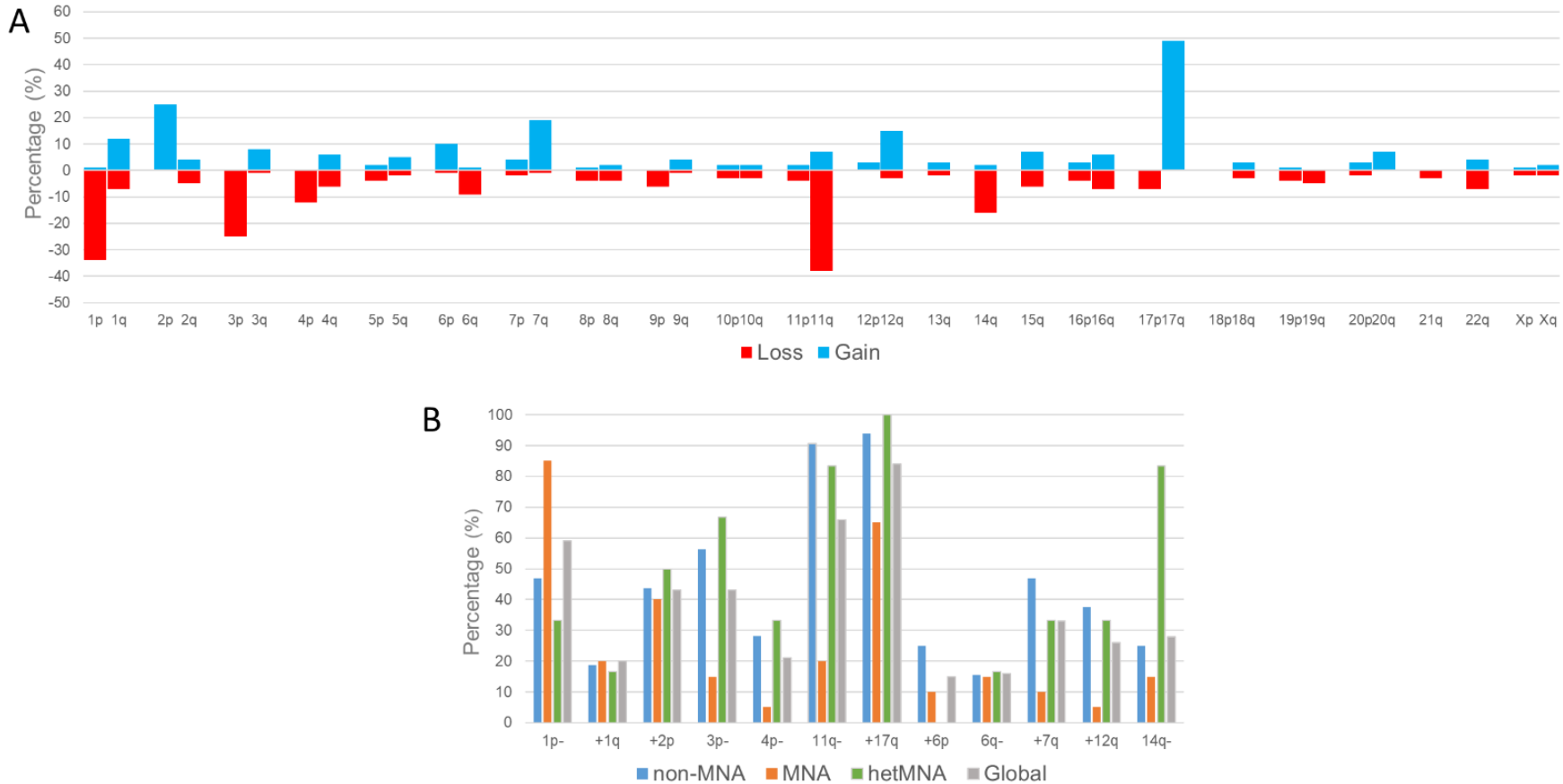

Figure 4. Percentage of the analysed cases that showed (A) segmental chromosomal aberrations in each chromosome arm (losses of genomic material are in red, and gains in blue). (B) Percentage of each segmental chromosome aberration observed in the cases MYCN non-amplified (non-MNA, blue), MYCN amplified (MNA, orange) or with heterogeneous amplification of MYCN (hetMNA, green), and in all the analyzed high-risk neuroblastoma cases (grey).

Furthermore, large chromosome segments or whole chromosome copy number loss of heterozygosity ( $\mathrm{cnLOH})$ was present in $18(31 \%)$ cases. A chromotripsis-like phenomenon involving eight chromosomes was detected in 6 cases ( 2 non-MNA, 3 MNA and 1 hetMNA) without ITH being observed in this genomic event. FSCAs affected 11 cases (18\%) of TERT, showing ITH in 2 of them. ATRX FSCAs were detected in 5 cases $(9 \%), 2$ of which displayed ITH. No FSCAs of either gene were detected in MNA cases. ALK mutation was found in 3 of 37 studied tumours ( 2 MNA and 1 non-MNA) and amplification in 2 out of 58 cases (both MNA). Finally, ALT was present in 5 out of 17 analysed cases (Figures 1-3).

\subsection{Improved ITH Detection in Non-MNA Samples with Combined Solid and Liquid Biopsy Analysis}

Of the 32 non-MNA primary tumours, 14 showed spatial ITH (43.75\%), found in $65 \%$ of non-MNA tumours when at least one solid and one liquid biopsy were analysed (11 out of 17), and $15 \%$ of cases with two or more solid areas analysed (2 out of 13). Total number of SCAs was higher in solid tumour DNA than in ctDNA in 4 tumours, with the opposite in 7. However, in some cases SCAs were only detectable in solid samples, and others only in liquid biopsy (Figure 1A). One patient (Figure 1A, case 7) showed differences between two tumour areas and in liquid biopsy. In the last ITH non-MNA case, liquid biopsy varied between bone marrow and peripheral blood samples (1 out of 2, Figure 1A, case 11).

TypSCAs and some atypSCAs were found in greater proportion in ITH than non-ITH cases (Table 3). Moreover, differences in genomic events between samples from ITH nonMNA tumours ranged from 1 to 14 , with ITH found in $7-73 \%$ of events (average 31\%). The most frequent ITH genomic events were $+7 q$ and $+2 p$ (in 5 cases). 4 cases also had ITH in TERT (cases 7 and 14) or ATRXs (cases 6 and 12) genes (Table 2, Figure 1A,B). 
Table 3. Percentage of the analysed cases with or without intratumor heterogeneity (ITH, and non-ITH, respectively) and without or with MYCN amplification (non-MNA and MNA, respectively) that showed typical segmental chromosomal aberrations (SCAs), the most frequently found atypical SCAs, and other genomic aberrations as focal SCAs in TERT and ATRX genes, number of cases with presence of alternative lengthening of telomeres (ALT positive), and presence of mutations (mut) or amplification (amp) in $A L K$ gene.

\begin{tabular}{|c|c|c|c|c|c|c|c|c|c|c|c|c|c|c|c|c|c|c|c|}
\hline \multirow{2}{*}{ Cases } & \multicolumn{7}{|c|}{ Typical SCAs } & \multicolumn{8}{|c|}{ Atypical SCAs } & \multicolumn{4}{|c|}{ Other Aberrations } \\
\hline & $1 \mathrm{p}-$ & $+1 q$ & $+2 p$ & $3 p-$ & $4 p-$ & $11 p-$ & $+17 q$ & $+6 p$ & $6 q-$ & $+7 q$ & $9 p-$ & $+12 q$ & $14 q-$ & $19 p-$ & $21 q-$ & TERT & ATRX & ALT & $A L K$ \\
\hline ITH non-MNA & $57 \%$ & $29 \%$ & $64 \%$ & $64 \%$ & $43 \%$ & $93 \%$ & $100 \%$ & $28 \%$ & $21 \%$ & $64 \%$ & $21 \%$ & $57 \%$ & $21 \%$ & $21 \%$ & $21 \%$ & $21 \%$ & $21 \%$ & 2 positive & $1 \mathrm{mut}, 0 \mathrm{amp}$ \\
\hline non-ITH non-MNA & $39 \%$ & $11 \%$ & $28 \%$ & $50 \%$ & $17 \%$ & $89 \%$ & $89 \%$ & $22 \%$ & $11 \%$ & $33 \%$ & $0 \%$ & $22 \%$ & $27 \%$ & $0 \%$ & $0 \%$ & $22 \%$ & $11 \%$ & 3 positive & $1 \mathrm{mut}, 0 \mathrm{amp}$ \\
\hline ITH MNA & $87 \%$ & $38 \%$ & $25 \%$ & $13 \%$ & $0 \%$ & $25 \%$ & $75 \%$ & $0 \%$ & $25 \%$ & $0 \%$ & $0 \%$ & $13 \%$ & $38 \%$ & $0 \%$ & $0 \%$ & $0 \%$ & $0 \%$ & pose & 0 mut, 0 amp \\
\hline non-ITH MNA & $83 \%$ & $8 \%$ & $50 \%$ & $17 \%$ & $8 \%$ & $17 \%$ & $58 \%$ & $8 \%$ & $8 \%$ & $16 \%$ & $16 \%$ & $0 \%$ & $0 \%$ & $0 \%$ & $0 \%$ & $0 \%$ & $0 \%$ & - & $1 \mathrm{mut}, 2 \mathrm{amp}$ \\
\hline
\end{tabular}

\subsection{ITH Detected in $40 \%$ of MNA Cases}

Of 20 MNA cases, 8 showed between-sample differences in pangenomic profile (Figure 2A,B). Specifically, we found SCA differences in 3 out of 6 of analysed cases with at least two solid samples (50\%), and in 5 of 14 with solid and liquid samples (36\%). One case (Figure 2A, patient 33) had no SCAs in one tumour sample and 4 SCAs in another. One case had more SCAs in tumour DNA than in ctDNA (Figure 2A, case 34), another case had an equal number of SCAs but some were different between tumour and liquid biopsy (Figure 2A, case 40 ) and 3 cases showed more SCAs in liquid biopsies than in solid ones.

Small differences between ITH and non-ITH cases were found in the number of SCAs: an average of 5.5 (median 5) vs. 5.3 (median 4.5), respectively, and in the type of typ- and atypSCAs (Table 3). The number of between-sample differences in genomic events ranged between 1 and 4 SCAs. ITH was found in $20-57 \%$ of events (average, 36\%), a similar proportion to that observed in non-MNA cases (31\%). No SCAs with especially high ITH between tumour biopsies were detected.

\subsection{Influence of ITH on EFS and OS}

Event free and overall survivals were followed up from 1 to 129 months (average 36.5 and 47.7 months, respectively). Notably, longer survival was observed at 36 and 60 months $($ EFS $p$-value $=0.043$, OS $p$-value $=0.041$, Figure $5 \mathrm{~A})$ in patients with ITH than in non-ITH patients. This survival difference was still significant taking only nonMNA cases, which showed a $43 \%$ survival rate in ITH cases compared with only $15 \%$ in non-ITH tumours (Figure 5B). However, survival was not statistically associated with ITH in MNA HR-NB despite a higher rate in ITH cases (62.5\%) than in non-ITH (50\%) ones (Figure 5C). HetMNA patients showed a 17\% survival rate. Following on from this observation, we undertook to study whether differences in prevalence of genomic events between samples from ITH tumours were associated with survival. Surprisingly, we observed $100 \%$ survival at 48 months in patients with ITH and at least $50 \%$ differences in genomic events, with significant differences in both EFS and OS ( $p$-value $=0.009$ and 0.006 , respectively) (Figure 5D). No significant survival differences were detected in patients with more SCAs in liquid than in solid samples or vice versa (Figure 5E). 
A

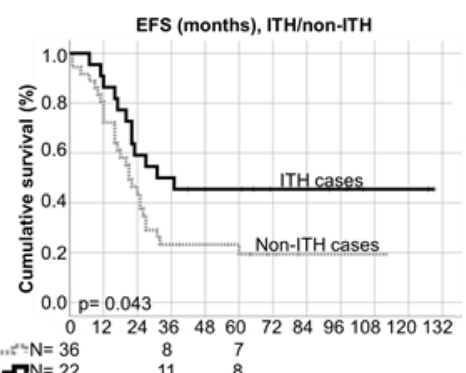

$\mathrm{B}$

EFS (months), ITH/non-ITH non-MNA cases

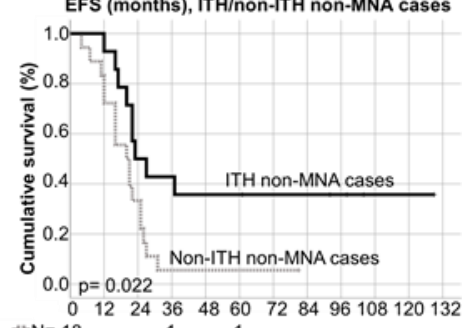

C

$$
\begin{array}{r}
0 \\
\boldsymbol{N} N=14
\end{array}
$$

$\begin{array}{ccc}8 & 46 & 48 \\ 4 & 1 & \\ 4 & 6 & 5\end{array}$
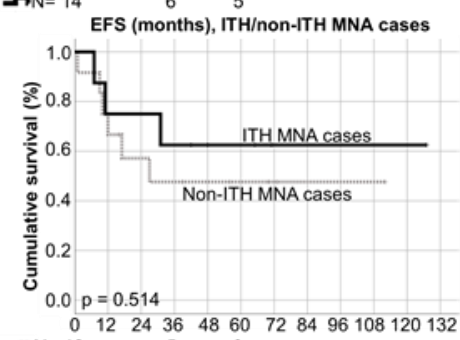

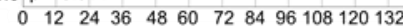

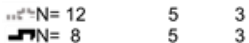

D

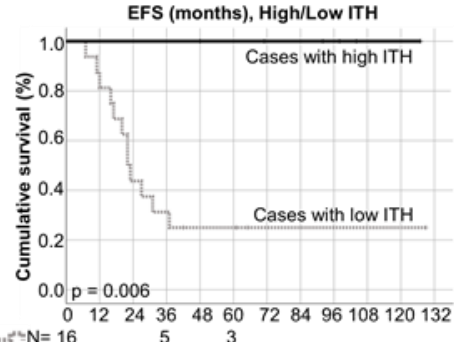

E

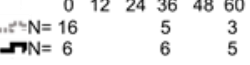

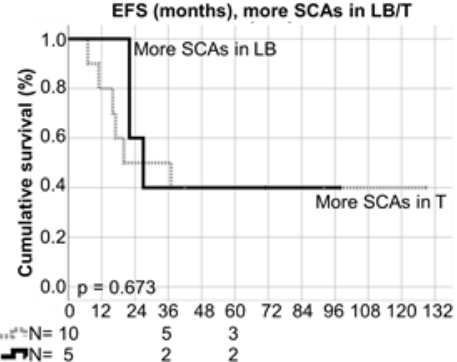

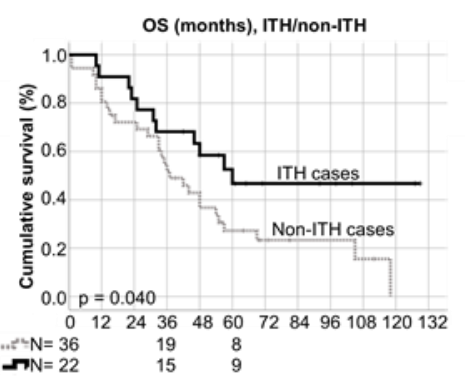

OS (months), ITH/non-ITH non-MNA cases

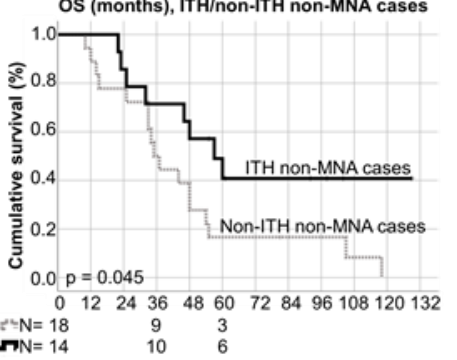

OS (months), ITH/non-ITH MNA cases

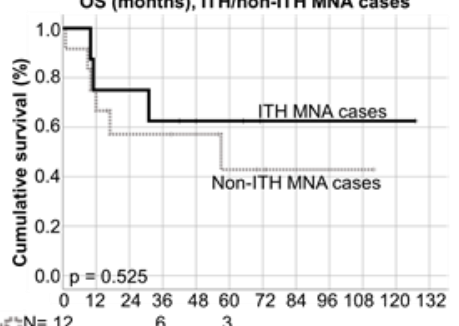

$\begin{array}{rrrr} & N=12 & 6 & 3 \\ \mathbb{N}=8 & 5 & 3\end{array}$
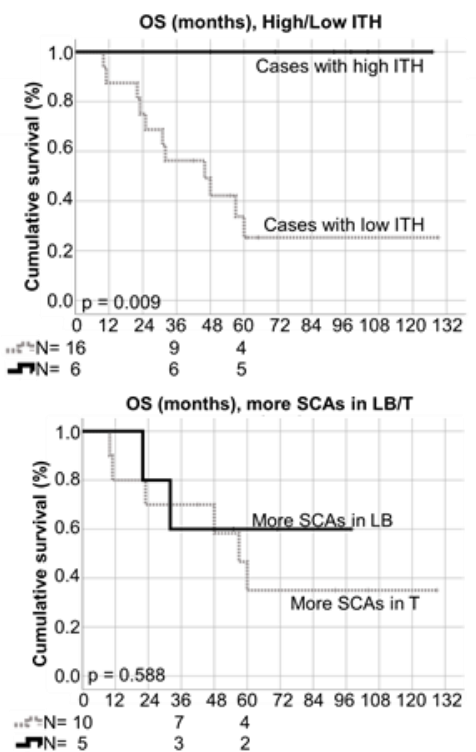

Figure 5. Kaplan-Meier graphs showing event free and overall survivals (left side, EFS and right side, OS) depending on different variables: (A) intra-tumour heterogeneity (ITH) detected or not detected (non-ITH) in all the studied cases; (B) ITH detected or not detected (non-ITH) in MYCN non-amplified (non-MNA) cases; (C) ITH detected or not detected (non-ITH) in MYCN amplified (MNA) cases; (D) high ITH (tumors with 50\% or more different genomic events between the analysed samples) versus low ITH (tumours with ITH but with less than 50\% different genomic events between the analysed samples); (E) higher number of segmental chromosomal aberrations (SCAs) observed in liquid biopsy (LB) versus higher number in solid tumour (T) samples. N: number of cases. 3-year and 5-year number of survivors, as well as $p$-values are shown. 
Overall, the higher survival in ITH patients was attributable to ITH rather than the other genomic factors that we studied, as was observed in both stepwise forward and backward (Wald) Cox regression analysis. However, EFS cox regression test (backward, Wald) also showed as significant $M Y C N$ status. In addition, we investigated the association with survival of number of SCAs, typSCAs and the most frequently found atypSCAs, presence of $\mathrm{cnLOH}$ and FSCAs in TERT and ATRX genes, none of which showed significant $p$-values $(p<0.05$, Table 4$)$.

Table 4. Cox regression tests results after applying stepwise forward and backward Wald methods. MYCN status (MYCN non-amplified (non-MNA), MYCN amplified (MNA) heterogeneous amplification of MYCN (hetMNA)) intra-tumour heterogeneity (ITH) and the segmental chromosomal aberrations $3 p-,+12 q$ and $14 q-$ are the variables that are maintained in the last step after applying the Wald backward stepwise method, according to event-free survival (EFS) in the studied high-risk neuroblastoma patients, being ITH and MYCN status the only significant ones ( $p$-value $<0.05)$. In the rest of the applied methods ITH is the only maintained variant. B: Beta coefficient; SE: Standard Error; CI: Confidence interval. Other variables without significant results included in the Cox regression analysis were: number of segmental chromosomal aberrations (SCAs) by quartiles, copy number loss of heterozygosity, aberrations in TERT and ATRX, typical SCAs $(1 \mathrm{p}-,+1 \mathrm{q},+2 \mathrm{p}, 4 \mathrm{p}-, 11 \mathrm{q}-,+17 \mathrm{q})$ and the atypical SCAs $(+6 p, 6 q-,+7 q)$.

\begin{tabular}{|c|c|c|c|c|c|}
\hline Variable & B & SE & Wald & $\operatorname{Exp}(B)(95 \% C I)$ & Sig. \\
\hline \multicolumn{6}{|c|}{ EFS Wald (forward stepwise) method } \\
\hline ITH & -0.677 & 0.347 & 3.811 & $0.508(0.257-1.003)$ & 0.051 \\
\hline \multicolumn{6}{|c|}{ EFS Wald (backward stepwise) method } \\
\hline ITH & -1.170 & 0.397 & 8.694 & $0.310(0.143-0.675)$ & 0.003 \\
\hline MYCN status & -0.628 & 0.278 & 5.102 & $0.534(0.310-0.920)$ & 0.024 \\
\hline $3 p-$ & -0.690 & 0.405 & 2.901 & $0.502(0.227-1.110)$ & 0.089 \\
\hline$+12 q$ & 0.702 & 0.423 & 2.759 & $2.019(0.881-4.624)$ & 0.097 \\
\hline $14 q^{-}$ & 0.816 & 0.438 & 3.469 & $2.262(0.958-5.339)$ & 0.063 \\
\hline \multicolumn{6}{|c|}{ OS Wald (forward stepwise) method } \\
\hline ITH & 0.716 & 0.358 & 4.000 & $0.489(0.242-0.986)$ & 0.046 \\
\hline \multicolumn{6}{|c|}{ OS Wald (backward stepwise) method } \\
\hline ITH & 0.716 & 0.358 & 4.000 & $0.489(0.242-0.986)$ & 0.046 \\
\hline
\end{tabular}

\section{Discussion}

An aberrant TME can promote genetic instability and could even compromise the DNA repair pathways needed to prevent malignant transformation [3,33,34]. Tumours can have different areas with disparate TME features, which could reflect differing genomic aberrations in tumour cells. It is well-known that the centre of the tumour typically has fewer blood vessels and more hypoxia than tumour borders [35], which can influence $\mathrm{pH}$ and metabolism, and also induce genomic and epigenomic changes between zones [36]. However, tissue areas of tumours submitted to genetic diagnostics yield little information even without taking ITH into account and this could be among the principal reasons for low reproducibility, not only in diagnostics and treatment but also in bio-medical research [1,37].

The INRG Biology Committee has already recommended ensuring that a sufficient amount of tumour material is analysed, as determined by a pathologist, from at least two different tumour regions in NB genetic diagnosis [38]. Guidelines have also been published on optimal tumour section for detecting genomic ITH [39]. However, it should be noted that NB are frequently found in neonates and young children, in whom total surgical excision or representative biopsy collection are restricted options [40]. These difficulties in NB tumour sampling result in underdetection of genomic aberrations located in metastatic clones, forming small foci, nodules (such as ganglioneuroblastoma, nodular), or dispersed in an isolated tumour area that could lead to erroneous genetic diagnosis and inadequate treatment selection $[41,42]$. 
In our study we detected genetic spatial genomic ITH with HD-SNPa in $21 \%$ of cases with at least two tumour pieces analysed, which permitted a greater representation of overall TME involvement. This considerable percentage shows the importance of analysing the largest possible area of the tumour, which can be achieved by mixing material from different tumour areas to obtain DNA from diverse TME locations. In 50\% of cases ITH detection was enhanced, when we obtained DNA from one or more tumour specimens and ctDNA from liquid biopsy. These results demonstrate not only the extent of tumour heterogeneity, but also the sensitivity of liquid biopsy in SCA detection, in agreement with reports over recent years [21,22,43-45]. Cases in which more genomic aberrations were detected in liquid biopsy than in solid tumour may reveal not only different clones of the biopsied tumour, but also that several clones may have invaded other parts of the body, or were trying to do so [46]. Nevertheless, in some cases we detected fewer genomic aberrations in liquid biopsy than solid tumour. Presence of genomic aberrations in the former biopsy could also be conditioned by the TME. The proportion of necrosis, variations in non-tumour cells, as well as permeable blood and lymphatic vessels, among others, determines the different amount of ctDNA in the liquid biopsy released by different tumour areas [47]. In addition, a heterogeneous TME may render liquid biopsy results incompletely representative of the entire tumour. Consequently, liquid biopsy should be a complementary source of tumour DNA, but not a substitute for the whole biopsy [48,49], and should only become an alternative in cases in which tumour tissue biopsy is precluded.

A recent study comparing genetic results derived from solid tumours and liquid samples of NB suggested that solid tumour-specific alterations could correspond to clones that might release less ctDNA, meaning less aggressive cells, while ctDNA-specific alterations could correspond to more aggressive clones or to those originating from metastatic sites [22]. We found no significant results comparing patient survival rates.

Interestingly, patients with ITH had better EFS and OS when we included all the studied cases in the Kaplan-Meier analysis, results that were replicated when patients with non-MNA tumours were analysed separately, but in contrast were not statistically significant for MNA cases, despite their higher rate of survival in ITH ones. Taking into account these results, we expanded our ITH analysis to study whether the number of between-sample differences in genomic events in the same patient was associated with survival. When at least $50 \%$ of genomic events differed between samples, indicating with high ITH tumours, all patients were found to survive.

Various hypotheses could explain this finding. Patients with greater ITH could survive due to the competition between several clones, possibly influenced by a heterogeneous TME. This has been described as occurring most typically during early tumour formation and proliferation, when tumour cells are trying to adapt to the niche, in contrast to nonheterogeneous tumours in which an aggressive and predominant clone has already become established, conferring worse prognosis $[1,3]$. Among cell populations trying to respond to adverse TME features, only the most pheno-genotypically adapted ones will succeed in invading tissues [50,51]. The most advantageous tumour cells will also segregate anchor proteins and transform the ECM into one with favourable biochemistry and biotensegrity, which will also promote homogeneous establishment of the powerful clones, allowing them to grow and migrate [20,33]. Another explanation could be that ITH cases, especially non-MNA ones, have high genomic instability as reflected in a high number of SCA cell profiles, which they cannot withstand and thus collapse earlier than tumours with lower SCA numbers. Both genomic instability and degree of tumour ITH have previously been associated with poor prognosis, conferring on the tumour more opportunities to adapt and resist chemotherapy [52-54]. However, extreme levels of genomic instability have been reported to be associated with increased OS [52] and patients with tumours displaying more than four different sub-clones have reduced mortality risk [55]. It has been observed that cancer cells with these levels of genomic instability rarely replicate successfully, and those tumours may also be more immunogenic [47], suggesting a trade-off between the costs and benefits of genomic instability [55]. This is exemplified by the phenomenon of 
chromotripsis as a chaotic genomic event. It has been shown that genomic chaos leads to reorganization that could persist over time, but also that cells with too much genomic instability are usually eliminated during cancer development [56]. A recent study published by our group in a MNA NB cell line grown in stiff TME models observed disappearance of clones with high SCAs and chromotripsis-like phenomena and positive selection of clones with specific SCAs affecting mechanosignalling genes [3].

Our findings support a revised approach to the currently reported frequency of several recurrent SCAs and their involvement in HR-NB. We detected greater incidence of certain atypical SCAs (such as gains at 7q, 12q, and loss at 14q) than of other typical SCAs like $1 \mathrm{q}$ gain or $4 \mathrm{p}$ loss. Moreover, some had differing prevalence in non-MNA, MNA and hetMNA tumours, and these associations should be taken into account. Gain at 7q was mainly found in non-MNA and hetMNA cases, and was differentially found across tumour samples. Various publications have also described a high presence of this aberration in $\mathrm{NB}$, especially in stage four $[57,58]$. Although gain at 12q is understudied in the scientific literature, amplification (also present in three of the present cases; see Figures 1B and 2B) and overexpression of some of its genes, is correlated with poor prognosis $[59,60]$. In our cohort, gain of this region was most present in ITH cases, and preferentially in non-MNA and hetMNA tumours. Deletion and loss of heterozygosity of 14q has been also previously reported to be involved in NB initiation and progression [61-63]. In the cohort studied herein, these alterations were most frequent in hetMNA cases. Finally, we also detected high frequency of FSCAs in TERT and ARTX genes, which are involved in telomere maintenance through telomerase activity and alternative lengthening of telomeres [64]. Both genes are considered important in understanding the etiology and molecular pathogenesis of $\mathrm{NB}$, and hence for identifying diagnostic and treatment markers. We found FSCAs in these genes differentially present among some analysed HR-NB samples. As development of telomerase inhibitors and identification of alternative lengthening of telomere-related targets becomes a reality [64], detection of both gene aberrations, even in ITH, by analysing several tumour samples will play a key role.

We detected ITH in almost $40 \%$ of our samples, and the true percentage could even be higher. The HD-SNPa obtained from each tumour sample reflects the chromosomic aberrations of an aggregate of minor clones that coexist in that piece, a metagenome. However, HD-SNPa software analysis leads to easy ITH detection with at least $30 \%$ allelic frequency, or even at lower proportions in good quality samples $[3,65]$, although very uncommon aberrations are difficult to detect. This would be the case in tumours without observed between-sample ITH, which could have small-scale heterogeneity, thus conferring poor prognosis. It has been reported that small sub-clones are usually associated with poor prognosis, as they can adapt but later evolve into tumour progression, or also lead to new sub-clones [55]. Moreover, we investigated SCAs as the most frequently found genetic aberrations in NB, and a great source of genomic instability; however, there are a wealth of alternative genetic, epigenetic and transcriptomic aberrations which could also confer ITH $[22,66,67]$. These data are especially pivotal in the current panorama in which identification of several well-known and other less explored genetic aberrations are essential for therapeutic stratification, as tools in patient clinical guidance and as potential treatment targets (typical SCA, ALK mutation, ALT alterations). Moreover, beyond its importance in diagnosis, prognosis and therapy, ITH detection can also provide greater insight into the internal composition of tumours [1]. In-depth research with powerful new genomic approaches, combined with digital pathology analysis of the TME may be key to understanding the molecular and cellular underpinnings of NB and other cancers. In addition, the association between ITH and improved prognosis in the cohort studied suggest that efforts aimed at modulating the cost/benefit trade-off of unstable tumours may represent a new therapeutic avenue [55]. 


\section{Conclusions}

As ITH is associated with survival in our HR-NB patients, and especially in non-MNA tumours, further studies with larger NB cohorts are clearly warranted to investigate its value as an independent prognosis factor. If ITH really implies increased survival, then this should be taken into consideration and review and possible adjustment of standard therapy should be encouraged. A more detailed study of ITH, potentially revealing genomic aberrations present in only a few cells, will also help decision-making on targeted treatment. Analysing multiple tumour samples (a mix of their DNAs) plus liquid biopsy to make a routine accurate genomic diagnosis seems an optimal approach to detect ITH and move towards improved precision medicine. Whole genome (or exome) sequencing, digital PCR and single-cell RNA-Seq are powerful techniques to detect and confirm genomic ITH, not only in SCAs but also in single nucleotide variants. Combined with digital image analysis of the TME, these genomic techniques will be useful to detect the ITH of the whole tumour, at genomic and morphological/topological levels, to predict the course of tumour clones and ultimately to determine prognosis and the best treatment options for each patient.

Author Contributions: Conceptualization, R.N.; methodology, A.L.-C., A.P.B., S.M.-V. and M.B.-M.; formal analysis A.L.-C., A.P.B., S.N., V.C. and R.N.; writing-original draft preparation A.L.-C.; writing-review and editing, A.L.-C. and R.N. All authors have read and agreed to the published version of the manuscript.

Funding: This study was supported by ISCIII (FIS) and FEDER (European Regional Development Fund): PI17/01558 and PI20/01107, CIBERONC (CB16/12/00484), NEN Association (Nico contra el cáncer infantil 2017-PVR00157) and Fundación Científica de la Asociación Española contra el Cáncer (FAECC2015/006). The funders had no involvement in the research process or the preparation and submission of the article.

Institutional Review Board Statement: This study was approved by the Ethical Committee of the University of Valencia (reference B.0000339, date of approval: 29 January 2015). Participants or their family members/legal guardians provided written informed consent for histological and genetic diagnostic studies performed in the laboratory.

Informed Consent Statement: Informed consent was obtained from all subjects (or their family members/legal guardians) involved in the study.

Data Availability Statement: No new data were created or analyzed in this study. Data sharing is not applicable to this article.

Acknowledgments: The authors thank the Spanish Society of Paediatric Haemato-Oncology (SEHOP) for patient data management, specially Desireé Ramal and Adela Cañete from Hospital Universitario y Politécnico la Fe de Valencia; Angelica Bellini and Gudrun Schleiermacher from Institute Curie of Paris, for $A L K$ results; Sally George, from the Royal Marsden Hospital of London, for ALT determinations; Elisa Alonso, from Pathological Anatomy Service of INCLIVA, for her technical support; Jesica Portero, from Central Unit of Research in Medicine of University of Valencia, for her technical support with HD-SNPa, and Kathryn Davies for English correction.

Conflicts of Interest: The authors declare no conflict of interest.

\section{References}

1. Zheng, Z.; Yu, T.; Zhao, X.; Gao, X.; Zhao, Y.; Liu, G. Intratumor heterogeneity: A new perspective on colorectal cancer research. Cancer Med. 2020, 9, 7637-7645. [CrossRef] [PubMed]

2. Von Stedingk, K.; Gisselsson, D.; Bexell, D. Multidimensional intratumour heterogeneity in neuroblastoma. Oncotarget 2019, 10, 3-5. [CrossRef] [PubMed]

3. López-Carrasco, A.; Martín-Vañó, S.; Burgos-Panadero, R.; Monferrer, E.; Berbegall, A.P.; Fernández-Blanco, B.; Navarro, S.; Noguera, R. Impact of extracellular matrix stiffness on genomic heterogeneity in $M Y C N$-amplified neuroblastoma cell line. J. Exp. Clin. Cancer Res. 2020, 39. [CrossRef] [PubMed]

4. Gerashchenko, T.S.; Denisov, E.V.; Litviakov, N.V.; Zavyalova, M.V.; Vtorushin, S.V.; Tsyganov, M.M.; Perelmuter, V.M.; Cherdyntseva, N.V. Intratumor heterogeneity: Nature and biological significance. Biochemistry 2013, 78, 1201-1215. [CrossRef] 
5. Berbegall, A.P.; Bogen, D.; Pötschger, U.; Beiske, K.; Bown, N.; Combaret, V.; Defferrari, R.; Jeison, M.; Mazzocco, K.; Varesio, L.; et al. Heterogeneous MYCN amplification in neuroblastoma: A SIOP Europe Neuroblastoma Study. Br. J. Cancer 2018, 118, 1502-1512. [CrossRef]

6. $\quad$ Berbegall, A.P.; Villamón, E.; Piqueras, M.; Tadeo, I.; Djos, A.; Ambros, P.F.; Martinsson, T.; Ambros, I.M.; Cañete, A.; Castel, V.; et al. Comparative genetic study of intratumoral heterogenous $M Y C N$ amplified neuroblastoma versus aggressive genetic profile neuroblastic tumors. Oncogene 2016, 35, 1423-1432. [CrossRef] [PubMed]

7. Colon, N.C.; Chung, D.H. Neuroblastoma. Adv. Pediatr. 2011, 58, 297-311. [CrossRef]

8. Cohn, S.L.; Pearson, A.D.J.; London, W.B.; Monclair, T.; Ambros, P.F.; Brodeur, G.M.; Faldum, A.; Hero, B.; Iehara, T.; Machin, D.; et al. The International Neuroblastoma Risk Group (INRG) classification system: An INRG task force report. J. Clin. Oncol. 2009, 27, 289-297. [CrossRef] [PubMed]

9. Von Stedingk, K.; De Preter, K.; Vandesompele, J.; Noguera, R.; Øra, I.; Koster, J.; Versteeg, R.; Påhlman, S.; Lindgren, D.; Axelson, $\mathrm{H}$. Individual patient risk stratification of high-risk neuroblastomas using a two-gene score suited for clinical use. Int. J. Cancer 2015, 137, 868-877. [CrossRef] [PubMed]

10. Thompson, D.; Vo, K.T.; London, W.B.; Fischer, M.; Ambros, P.F.; Nakagawara, A.; Brodeur, G.M.; Matthay, K.K.; DuBois, S.G. Identification of patient subgroups with markedly disparate rates of MYCN amplification in neuroblastoma: A report from the International Neuroblastoma Risk Group project. Cancer 2016, 122, 935-945. [CrossRef]

11. Ackermann, S.; Cartolano, M.; Hero, B.; Welte, A.; Kahlert, Y.; Roderwieser, A.; Bartenhagen, C.; Walter, E.; Gecht, J.; Kerschke, L.; et al. A mechanistic classification of clinical phenotypes in neuroblastoma. Science 2018, 362, 1165-1170. [CrossRef] [PubMed]

12. Arneth, B. Tumor microenvironment. Medicina 2020, 56, 15. [CrossRef]

13. Brassart-Pasco, S.; Brézillon, S.; Brassart, B.; Ramont, L.; Oudart, J.B.; Monboisse, J.C. Tumor Microenvironment: Extracellular Matrix Alterations Influence Tumor Progression. Front. Oncol. 2020, 10, 397. [CrossRef]

14. Tadeo, I.; Berbegall, A.P.; Castel, V.; García-Miguel, P.; Callaghan, R.; Påhlman, S.; Navarro, S.; Noguera, R. Extracellular matrix composition defines an ultra-high-risk group of neuroblastoma within the high-risk patient cohort. Br. J. Cancer 2016, 115, 480-489. [CrossRef]

15. Tadeo, I.; Bueno, G.; Berbegall, A.P.; Fernández-Carrobles, M.M.; Castel, V.; García-Rojo, M.; Navarro, S.; Salvá, R.N. Vascular patterns provide therapeutic targets in aggressive neuroblastic tumors. Oncotarget 2016, 7, 19935-19947. [CrossRef] [PubMed]

16. Tadeo, I.; Gamero-Sandemetrio, E.; Berbegall, A.P.; Gironella, M.; Ritort, F.; Cañete, A.; Bueno, G.; Navarro, S.; Noguera, R. Lymph microvascularization as a prognostic indicator in neuroblastoma. Oncotarget 2018, 9, 26157-26170. [CrossRef] [PubMed]

17. Burgos-Panadero, R.; Noguera, I.; Cañete, A.; Navarro, S.; Noguera, R. Vitronectin as a molecular player of the tumor microenvironment in neuroblastoma. BMC Cancer 2019, 19. [CrossRef] [PubMed]

18. Tadeo, I.; Gamero-Sandemetrio, E.; Berbegall, A.P.; Navarro, S.; Cañete, A.; Noguera, R. 1p36 deletion results in a decrease in glycosaminoglycans which is associated with aggressiveness in neuroblastic tumors. Histol. Histopathol. 2018, 33, 487-495.

19. Monferrer, E.; Sanegre, S.; Martín-Vañó, S.; García-Lizarribar, A.; Burgos-Panadero, R.; López-Carrasco, A.; Navarro, S.; Samitier, J.; Noguera, R. Digital image analysis applied to tumor cell proliferation, aggressiveness, and migration-related protein synthesis in neuroblastoma 3d models. Int. J. Mol. Sci. 2020, 21, 8676. [CrossRef] [PubMed]

20. Simi, A.K.; Pang, M.F.; Nelson, C.M. Extracellular matrix stiffness exists in a feedback loop that drives tumor progression. Adv. Exp. Med. Biol. 2018, 1092, 57-67.

21. Chicard, M.; Boyault, S.; Daage, L.C.; Richer, W.; Gentien, D.; Pierron, G.; Lapouble, E.; Bellini, A.; Clement, N.; Iacono, I.; et al. Genomic copy number profiling using circulating free tumor DNA highlights heterogeneity in neuroblastoma. Clin. Cancer Res. 2016, 22, 5564-5573. [CrossRef] [PubMed]

22. Chicard, M.; Colmet-Daage, L.; Clement, N.; Danzon, A.; Bohec, M.; Bernard, V.; Baulande, S.; Bellini, A.; Deveau, P.; Pierron, G.; et al. Whole-exome sequencing of cell-free DNA reveals temporo-spatial heterogeneity and identifies treatment-resistant clones in neuroblastoma. Clin. Cancer Res. 2018, 24, 939-949. [CrossRef] [PubMed]

23. Herrera, M.; Galindo-Pumariño, C.; García-Barberán, V.; Peña, C. A snapshot of the tumor microenvironment in colorectal cancer: The liquid biopsy. Int. J. Mol. Sci. 2019, 20, 6016. [CrossRef] [PubMed]

24. Cariati, F.; Borrillo, F.; Shankar, V.; Nunziato, M.; D'argenio, V.; Tomaiuolo, R. Dissecting intra-tumor heterogeneity by the analysis of copy number variations in single cells: The neuroblastoma case study. Int. J. Mol. Sci. 2019, 20, 893. [CrossRef] [PubMed]

25. Vandesompele, J.; Speleman, F.; Van Roy, N.; Laureys, G.; Brinkschmidt, C.; Christiansen, H.; Lampert, F.; Lastowska, M.; Bown, N.; Pearson, A.; et al. Intratumoural heterogeneity of $1 \mathrm{p}$ deletions and MYCN amplication in neuroblastomas. Med. Pediatr. Oncol. 2001,36, 1-4.

26. George, R.E.; Attiyeh, E.F.; Li, S.; Moreau, L.A.; Neuberg, D.; Li, C.; Fox, E.A.; Meyerson, M.; Diller, L.; Fortina, P.; et al. Genome-wide analysis of neuroblastomas using high-density single nucleotide polymorphism arrays. PLoS ONE 2007,2 , e255. [CrossRef]

27. Durand, S.; Pierre-Eugène, C.; Mirabeau, O.; Louis-Brennetot, C.; Combaret, V.; Colmet-Daage, L.; Blanchard, O.; Bellini, A.; Daudigeos-Dubus, E.; Raynal, V.; et al. ALK mutation dynamics and clonal evolution in a neuroblastoma model exhibiting two ALK mutations. Oncotarget 2019, 10, 4937-4950. [CrossRef]

28. Mengelbier, L.H.; Karlsson, J.; Lindgren, D.; Valind, A.; Lilljebjörn, H.; Jansson, C.; Bexell, D.; Braekeveldt, N.; Ameur, A.; Jonson, T.; et al. Intratumoral genome diversity parallels progression and predicts outcome in pediatric cancer. Nat. Commun. 2015, 6 , 1-10. [CrossRef] 
29. Villamón, E.; Berbegall, A.P.; Piqueras, M.; Tadeo, I.; Castel, V.; Djos, A.; Martinsson, T.; Navarro, S.; Noguera, R. Genetic Instability and Intratumoral Heterogeneity in Neuroblastoma with MYCN Amplification Plus 11q Deletion. PLOS ONE 2013, 8, e53740. [CrossRef]

30. Ambros, I.M.; Brunner, B.; Aigner, G.; Bedwell, C.; Beiske, K.; Bénard, J.; Bown, N.; Combaret, V.; Couturier, J.; Defferrari, R.; et al. A multilocus technique for risk evaluation of patients with neuroblastoma. Clin. Cancer Res. 2011, 17, 792-804. [CrossRef]

31. Bellini, A.; Pötschger, U.; Bernard, V.; Lapouble, E.; Baulande, S.; Ambros, P.F.; Auger, N.; Beiske, K.; Bernkopf, M.; Betts, D.R.; et al. Frequency and Prognostic Impact of $A L K$ Amplifications and Mutations in the European Neuroblastoma Study Group (SIOPEN) High-Risk Neuroblastoma Trial (HR-NBL1). J. Clin. Oncol. 2021. [CrossRef]

32. Henson, J.D.; Lau, L.M.; Koch, S.; Martin La Rotta, N.; Dagg, R.A.; Reddel, R.R. The C-Circle Assay for alternative-lengthening-oftelomeres activity. Methods 2017, 114, 74-84. [CrossRef]

33. Pickup, M.W.; Mouw, J.K.; Weaver, V.M. The extracellular matrix modulates the hallmarks of cancer. EMBO Rep. 2014, 15, 1243-1253. [CrossRef]

34. Filipe, E.C.; Chitty, J.L.; Cox, T.R. Charting the unexplored extracellular matrix in cancer. Int. J. Exp. Pathol. 2018, 99, 58-76. [CrossRef]

35. Persano, L.; Rampazzo, E.; Della Puppa, A.; Pistollato, F.; Basso, G. The three-layer concentric model of glioblastoma: Cancer stem cells, microenvironmental regulation, and therapeutic implications. Sci. World J. 2011, 11, 1829-1841. [CrossRef]

36. Monferrer, E.; Vieco-Martí, I.; López-Carrasco, A.; Fariñas, F.; Abanades, S.; de la Cruz-Merino, L.; Noguera, R.; Naranjo, T.Á Metabolic classification and intervention opportunities for tumor energy dysfunction. Metabolites 2021, 11, 264. [CrossRef] [PubMed]

37. Stanta, G.; Bonin, S. Overview on clinical relevance of intra-tumor heterogeneity. Front. Med. 2018, 5. [CrossRef] [PubMed]

38. Ambros, P.F.; Ambros, I.M.; Brodeur, G.M.; Haber, M.; Khan, J.; Nakagawara, A.; Schleiermacher, G.; Speleman, F.; Spitz, R.; London, W.B.; et al. International consensus for neuroblastoma molecular diagnostics: Report from the International Neuroblastoma Risk Group (INRG) Biology Committee. Br. J. Cancer 2009, 100, 1471-1482. [CrossRef] [PubMed]

39. Lopez, J.I.; Cortes, J.M. A divide-and-conquer strategy in tumor sampling enhances detection of intratumor heterogeneity in routine pathology: A modeling approach in clear cell renal cell carcinoma. F1000Research 2016, 5, 385. [CrossRef] [PubMed]

40. Emre, Ş.; Özcan, R.; Bakır, A.C.; Kuruğoğlu, S.; Çomunoğlu, N.; Şen, H.S.; Celkan, T.; Tekant, G.T. Adrenal masses in children: Imaging, surgical treatment and outcome. Asian J. Surg. 2020, 43, 207-212. [CrossRef]

41. Coco, S.; Defferrari, R.; Scaruffi, P.; Cavazzana, A.; Di Cristofano, C.; Longo, L.; Mazzocco, K.; Perri, P.; Gambini, C.; Moretti, S.; et al. Genome analysis and gene expression profiling of neuroblastoma and ganglioneuroblastoma reveal differences between neuroblastic and Schwannian stromal cells. J. Pathol. 2005, 207, 346-357. [CrossRef]

42. Rybinski, B.; Wolinsky, T.; Brohl, A.; Moerdler, S.; Reed, D.R.; Ewart, M.; Weiser, D. Multifocal primary neuroblastoma tumor heterogeneity in siblings with co-occurring PHOX2B and NF1 genetic aberrations. Genes Chromosom. Cancer 2020, 59, 119-124. [CrossRef]

43. Cohen, P.A.; Flowers, N.; Tong, S.; Hannan, N.; Pertile, M.D.; Hui, L. Abnormal plasma DNA profiles in early ovarian cancer using a non-invasive prenatal testing platform: Implications for cancer screening. BMC Med. 2016, 14. [CrossRef]

44. Oellerich, M.; Schütz, E.; Beck, J.; Kanzow, P.; Plowman, P.N.; Weiss, G.J.; Walson, P.D. Using circulating cell-free DNA to monitor personalized cancer therapy. Crit. Rev. Clin. Lab. Sci. 2017, 54, 205-218. [CrossRef]

45. Xia, Y.; Huang, C.C.; Dittmar, R.; Du, M.; Wang, Y.; Liu, H.; Shenoy, N.; Wang, L.; Kohli, M. Copy number variations in urine cell free DNA as biomarkers in advanced prostate cancer. Oncotarget 2016, 7, 35818-35831. [CrossRef]

46. Russano, M.; Napolitano, A.; Ribelli, G.; Iuliani, M.; Simonetti, S.; Citarella, F.; Pantano, F.; Dell'aquila, E.; Anesi, C.; Silvestris, N.; et al. Liquid biopsy and tumor heterogeneity in metastatic solid tumors: The potentiality of blood samples. J. Exp. Clin. Cancer Res. 2020, 39, 1-13. [CrossRef]

47. Elazezy, M.; Joosse, S.A. Techniques of using circulating tumor DNA as a liquid biopsy component in cancer management. Comput. Struct. Biotechnol. J. 2018, 16, 370-378. [CrossRef] [PubMed]

48. Arechederra, M.; Ávila, M.A.; Berasain, C. Liquid biopsy for cancer management: A revolutionary but still limited new tool for precision medicine. Adv. Lab. Med. Av. Med. Lab. 2020, 1. [CrossRef]

49. Mino-Kenudson, M. Cons: Can liquid biopsy replace tissue biopsy?-the US experience. Transl. Lung Cancer Res. 2016, 5, 424-427. [CrossRef] [PubMed]

50. Schulte, M.; Köster, J.; Rahmann, S.; Schramm, A. Cancer evolution, mutations, and clonal selection in relapse neuroblastoma. Cell Tissue Res. 2018, 372, 263-268. [CrossRef] [PubMed]

51. Greaves, M. Nothing in cancer makes sense except. BMC Biol. 2018, 16. [CrossRef]

52. Andor, N.; Maley, C.C.; Ji, H.P. Genomic instability in cancer: Teetering on the limit of tolerance. Cancer Res. 2017, 77, 2179-2185. [CrossRef]

53. Bakhoum, S.F.; Cantley, L.C. The Multifaceted Role of Chromosomal Instability in Cancer and Its Microenvironment. Cell 2018, 174, 1347-1360. [CrossRef]

54. Fernández-Blanco, B.; Berbegall, A.P.; Martin-Vañó, S.; Castel, V.; Navarro, S.; Noguera, R. Imbalance between genomic gain and loss identifies high-risk neuroblastoma patients with worse outcomes. Neoplasia 2021, 23, 12-20. [CrossRef]

55. Andor, N.; Graham, T.A.; Jansen, M.; Xia, L.C.; Athena Aktipis, C.; Petritsch, C. Pan-cancer analysis of the extent and consequences of intratumor heterogeneity. Nat. Med. 2016, 22, 105-113. [CrossRef] 
56. Liu, G.; Stevens, J.B.; Horne, S.D.; Abdallah, B.Y.; Ye, K.J.; Bremer, S.W.; Ye, C.J.; Chen, D.J.; Heng, H.H. Genome chaos: Survival strategy during crisis. Cell Cycle 2014, 13, 528-537. [CrossRef]

57. Stallings, R.L.; Howard, J.; Dunlop, A.; Mullarkey, M.; McDermott, M.; Breatnach, F.; O'Meara, A. Are gains of chromosomal regions 7q and 11p important abnormalities in neuroblastoma? Cancer Genet. Cytogenet. 2003, 140, 133-137. [CrossRef]

58. Costa, R.A.; Seuánez, H.N. Investigation of major genetic alterations in neuroblastoma. Mol. Biol. Rep. 2018, 45, $287-295$. [CrossRef]

59. Amoroso, L.; Ognibene, M.; Morini, M.; Conte, M.; Di Cataldo, A.; Tondo, A.; D’Angelo, P.; Castellano, A.; Garaventa, A.; Lasorsa, V.A.; et al. Genomic coamplification of CDK4/MDM2/FRS2 is associated with very poor prognosis and atypical clinical features in neuroblastoma patients. Genes Chromosom. Cancer 2020, 59, 277-285. [CrossRef] [PubMed]

60. Su, W.T.; Alaminos, M.; Mora, J.; Cheung, N.K.; La Quaglia, M.P.; Gerald, W.L. Positional gene expression analysis identifies 12q overexpression and amplification in a subset of neuroblastomas. Cancer Genet. Cytogenet. 2004, 154, 131-137. [CrossRef] [PubMed]

61. Carr, J.; Bown, N.P.; Case, M.C.; Hall, A.G.; Lunec, J.; Tweddle, D.A. High-resolution analysis of allelic imbalance in neuroblastoma cell lines by single nucleotide polymorphism arrays. Cancer Genet. Cytogenet. 2007, 172, 127-138. [CrossRef] [PubMed]

62. Theobald, M.; Christiansen, H.; Schmidt, A.; Melekian, B.; Wolkewitz, N.; Christiansen, N.M.; Brinkschmidt, C.; Berthold, F.; Lampert, F. Sublocalization of Putative Tumor Suppressor Gene Loci on Chromosome Arm 14q in Neuroblastoma. Genes Chromosom. Cancer 1999, 26, 40-46. [CrossRef]

63. Srivatsan, E.S.; Ying, K.L.; Seeger, R.C. Deletion of chromosome 11 and of 14q sequences in neuroblastoma. Genes Chromosom. Cancer 1993, 7, 32-37. [CrossRef] [PubMed]

64. Duan, X.F.; Zhao, Q. TERT-mediated and ATRX-mediated Telomere Maintenance and Neuroblastoma. J. Pediatr. Hematol. Oncol. 2018, 40, 1-6. [CrossRef] [PubMed]

65. Levy, B.; Wapner, R. Prenatal diagnosis by chromosomal microarray analysis. Fertil. Steril. 2018, 109, 201-212. [CrossRef] [PubMed]

66. Tsubota, S.; Kadomatsu, K. Origin and initiation mechanisms of neuroblastoma. Cell Tissue Res. 2018, 372, 211-221. [CrossRef] [PubMed]

67. Bosse, K.R.; Maris, J.M. Advances in the translational genomics of neuroblastoma: From improving risk stratification and revealing novel biology to identifying actionable genomic alterations. Cancer 2016, 122, 20-33. [CrossRef] [PubMed] 